\title{
Carob pulp syrup: A potential Mediterranean carbon source for carotenoids production by Rhodosporidium toruloides NCYC 921
}

\author{
Vasco Martins, Carla Dias, João Caldeira, Luís C. Duarte, Alberto Reis, Teresa Lopes da Silva* \\ Laboratório Nacional de Energia e Geologia, Unidade de Bioenergia, Estrada do Paço do Lumiar 22, 1649-038 Lisbon, Portugal
}

\section{A R T I C L E I N F O}

\section{Keywords:}

Carob pulp syrup

Rhodosporidium toruloides

Carotenoids

Flow cytometry

Cell viability

\begin{abstract}
A B S T R A C T
Carob pulp syrup (CPS) was used as carbon source to produce carotenoids from Rhodosporidium toruloides. To increase the carbon concentration in the growth medium aiming at the carotenoid production improvement, the CPS was concentrated and two different total sugar (TS) concentrations (195.6 g/L and 548.7 g/L) were studied. CPS $195.6 \mathrm{~g} / \mathrm{L}$ TS contained $4.1 \mathrm{~g} / \mathrm{L}$ and $0.7 \mathrm{~g} / \mathrm{L}$ of hydroxymethyl furfural (HMF) and furfural, respectively. CPS $548.7 \mathrm{~g} / \mathrm{L}$ TS contained $17.7 \mathrm{~g} / \mathrm{L}$ of HMF and $1.2 \mathrm{~g} / \mathrm{L}$ of furfural, respectively.

$>42 \%$ of metabolically active cells (with intact membrane and enzymatic activity) were detected throughout the course of the yeast cultivation on CPS $195.6 \mathrm{~g} / \mathrm{L}$ TS. On the contrary, the proportion of metabolically active cells was always below $28 \%$ during the yeast cultivation on CPS $548.7 \mathrm{~g} / \mathrm{L}$ TS.

Nevertheless, the maximum carotenoid content and productivity $(0.42 \mathrm{mg} / \mathrm{g}$ and $0.43 \mathrm{mg} / \mathrm{Lh}$, respectively) were obtained when using CPS $548.7 \mathrm{~g} / \mathrm{L}$ TS.
\end{abstract}

\section{Introduction}

Carotenoids, tetra-terpenoid $\mathrm{C}_{40}$ pigments containing isoprene residues and a polyene chain of conjugated double bounds, are natural fat-soluble, yellow and red substances, being synthesized from higher plants and microorganisms. Previous studies demonstrated that these compounds enhance the human immune response, the conversion to vitamin $\mathrm{A}$, the scavenging of oxygen radicals and also reduce the risks for degenerative diseases such as cancer, cardiovascular diseases, macular degeneration and cataract (Frengova and Beshkova, 2009; MataGómez et al., 2014). There is an increasing demand for carotenoids obtained from natural sources (including from microorganisms) due to the concerns of health-conscious consumers regarding the use of synthetic food dyes in pharmaceutical, food and feed industries (Vachali et al., 2012).

The oleaginous red yeast Rhodosporidium toruloides NCYC 921 has been widely described as a potential triacylglycerols and carotenoids producer (Freitas et al., 2014a; Dias et al., 2015). A way to reduce the process costs consists of using low-cost agricultural waste residues as substrates to grow the microorganism. Palm oil mill (Saenge et al., 2011a), crude glycerol (Saenge et al., 2011b), wastewater brewery effluent (Schneider et al., 2013) and potato wastewater (Kot et al., 2017) have been used as substrate to produce lipids and carotenoids from the red yeast Rhodotorula glutinis (anamorph: Rhodosporidium toruloides).
A low-cost carbon substrate rich in sugars that can be used in media formulation is the carob pulp syrup (CPS). The carob tree (Ceratonia siliqua L.) is native to the Mediterranean region being grown in countries such as Turkey, Spain, Greece, Morocco, Portugal, and Italy and also in many regions of North America (Turhan et al., 2010). The seeds of carob ( $10 \%$ of the fruit dry weight) produce $12 \%$ of the world market of gum and are widely used in the food industry (Sánchez et al., 2010). The pulp (the remaining $90 \%$ of the fruit dry weight) contains high content of sugar (sucrose, glucose and fructose) and tannins and low content of protein and fat, which limits its application as animal feed. The easily extractable sugars from the pulp makes this material eligible for the production of syrups that can be used as substrate for fermentation (Freitas et al., 2014b; Lima et al., 2012). Despite the high availability of the carob pulp residues resulting from local agro-food industries in these countries, their use as carbon source in media formulations for microbial cultivations is still scarce.

The present work studied carotenoids production from the red yeast Rhodosporidium toruloides NCYC 921 grown on CPS. The yeast was developed in a $7 \mathrm{~L}$ bioreactor working under fed-batch regime, using carob pulp syrup as carbon source. In order to improve the yeast carotenoids production, the carbon concentration was increased in the medium growth by concentrating the CPS, and two different total sugar concentrations (195.6 g/L and $548.7 \mathrm{~g} / \mathrm{L}$ ) were studied for comparison. Since the carob pulp contains microbial growth inhibitor compounds,

\footnotetext{
* Corresponding author.

E-mail address: teresa.lopessilva@lneg.pt (T. Lopes da Silva).
} 